\title{
Exploring Teachers Practices of Classroom Assessment in Secondary Science Classes in Bangladesh
}

\author{
Md. Mehadi Rahman ${ }^{1}$ \\ ${ }^{1}$ Institute of Education and Research (IER), University of Dhaka, Bangladesh \\ Correspondence: Md. Mehadi Rahman, Institute of Education and Research (IER), University of Dhaka, \\ Bangladesh.
}

Received: February 28, 2018

Accepted: May 16, 2018 Online Published: July 20, 2018

doi:10.5539/jel.v7n4p274

URL: https://doi.org/10.5539/jel.v7n4p274

\begin{abstract}
The study investigates teachers' classroom assessment practices of secondary schools in Bangladesh. The study is mainly quantitative with some integration of qualitative approach. Secondary science teachers and their science classrooms were main data source of the study, which were selected randomly. Data sources were secondary science teachers and their science classrooms. The study used a lesson observation protocol to understand their classroom assessment practice, and pre-lesson and post-lesson observation interview protocols as main sources of data collection. Qualitative data from interview were used to triangulate the quantitative data from observation. A total of thirty teachers (twenty male and ten female) were chosen randomly from six secondary schools in Dhaka. The study explored that teachers' current practice of classroom assessment was to only assess students learning achievement and they followed traditional methods to assess students. The dominated assessment activity was oral questioning and very few students take part in the assessment activities by answering the questions. The classroom questions are basically focused very specific responses and encouraged rote learning; even students' didn't get enough time for thinking and answering the questions. Therefore the study suggests changing current practices by using different assessment strategies like self and peer assessment and focus on assessment for learning to ensure effective teaching-learning and quality education. These findings can inform the classroom teachers as well as o relevant stakeholders in making necessary changes in the present classroom assessment practices in Bangladesh.
\end{abstract}

Keywords: assessment, classroom assessment, science classes, secondary education, teaching science, teachers practice

\section{Introduction}

Classroom assessment is a part of good teaching. Classroom assessment is defined as any planned method or strategy used in the classroom to establish the level of students' difficulties or understanding of a particular concept or idea with the purpose of helping students to succeed in learning (Ainscow, 1988). Susuwele-Banda (2005) mentioned that classroom assessment helps teachers to confirm what students already know and what they need to learn. Classroom assessment is an important part of science teaching and learning. Most assessment of science learning are carried out by teachers of science in classrooms, it is the teacher who is responsible for either initiating or implementing changes in assessment in the classroom and it is teacher who has to ultimately judge the educational worth, significance, and use of different assessment practice (Bell, 2002).

There are two types of assessment in general, formative assessment and summative assessment (Ahsan, 2009). Wiliam (2010) stated that formative and summative are two broad types' purposes of classroom assessment. When assessment is used for a formative purpose it focuses on enhancing instruction and improving learning whereas summing up learning achievements is the focus of a summative purpose. Stiggins (1991) stated that teachers use assessment in their classrooms to serve at least three different categories of purposes: (a) as a means of informing decisions (e.g., they diagnose students' needs, select students for special services, group students for instruction, and assign grades); (b) as teaching tools (e.g., to communicate achievement expectations to students, to provide practice for students, to involve students in self and peer evaluation to help them become better performers); and (c) as a classroom management or behavior control mechanism to keep students in line.

When classroom assessment is frequent and varied, teachers can learn a great deal about their students. Earl and Katz (2006) suggested that teachers can gain an understanding of students' existing beliefs and knowledge, and 
can identify incomplete understandings, false beliefs, and naive interpretations of concepts that may influence or distort learning. Teachers can observe and probe students' thinking over time, and can identify links between prior knowledge and new learning. Chappuis and Stiggins (2002) stated that teachers need to engage students in the process of classroom assessment and focused on enhancing learning for encouraging them to learning instead of only measuring their achievement. Brown (2004) also suggested that importance should be given on why assess along with what and how assess. The ways teachers assess students can really make a difference to how students learn. Classroom assessment's main application is to facilitate learning which can be described as assessment for learning.

Assessment for learning occurs throughout the learning process. Earl and Katz (2006) stated that assessment for learning is designed to make each student's understanding visible, so that teachers can decide what they can do to help students progress. In assessment for learning, teachers use assessment as an investigative tool to find out as much as they can about what their students know and can do, and what confusions, preconceptions, or gaps they might have. So, teachers use variety of strategies to assess students in the science classroom which includes observation, questioning, exercises, projects and investigation, library and web-based research assignment, and portfolios (Hackling, 2004).

The wide variety of information that teachers collect about their students' learning processes provides the basis for determining what they need to do next to move student learning forward. So, Chappuis and Stiggins (2002) suggested that assessment for learning means more than just assessing students often, more than just providing the teacher with assessment results to change revise instruction. In assessment for learning, both teacher and student use classroom assessment information to modify teaching and learning activities.

There is lots of evidence that there is lack in practice of classroom assessment in secondary level of Bangladesh. Most of the teachers are reluctant in assessing students properly. They mainly highlight on students' performance in the examination rather than emphasizing on students learning. Teachers are not oriented with effective classroom assessment strategies and for this reason students are focused on result rather than learning. Ahsan (2009) found that our assessment culture promotes assessment of learning and inhibits assessment for learning. Black and Wiliam (1998) mention it as "a poverty of practice" (p.2). Therefore, it is important to examine how teachers practice classroom assessment using different strategies and tools in science classes. As classroom assessment enhance students learning, the study will find out to what extent the current classroom assessment practices are useful for students learning.

\section{Purpose and Research Question}

The purpose of this study is to explore the classroom assessment practices in secondary science classes in Bangladesh. To achieve the purpose of this study, more specifically, intends to answer the following key questions:

1) How do the teachers assess their students' science learning in secondary school classrooms?

2) How do the teachers provide feedback to their students during classroom assessment in secondary science classrooms?

\section{Methodology}

The study is mainly depended on descriptive inquiry to elicit data related to teachers' classroom assessment practices of secondary schools in Bangladesh. It is carried out based on mainly quantitative with some qualitative approach.

A sample of 30 science teachers was selected from six schools which were located in Dhaka city using random sampling. Five science teachers were chosen from each school randomly. One science period (classroom) of each teacher was observed followed by a pre and post observation interview with teachers. Total 30 science periods (classroom) were selected using random sampling.

An observation checklist following 4 point Likert type scale for classroom assessment procedure is used in selected classrooms. Moreover, field note approach for detailed description of the assessment tasks as well as any other significant evidence is employed. Two separate semi structure interview schedules are used for pre and post observation interview of the selected teachers. The data obtained from observation protocol were analyzed based on the weighted mean of the statements (Grela, 2013). The qualitative data obtained through interview was analyzed using predetermined themes that addressed the themes of classroom observation. Qualitative data helped the researcher to support quantitative data and also in triangulation of data. 


\section{Results}

The results of this study are presented based on the major focuses of science classroom assessment activities.

\subsection{Teaching-Learning Activities}

Teaching learning activity is the main part of a class. It is the task what teacher and student supposed to do in the class. Teachers facilitate the students in their learning process in this part. The cumulative mean of teaching-learning activities in the class is 2.18 and SD 0.909. This mean indicates that teachers did some activities in the teaching learning activity but improvement is required. However, the overall mean didn't reflect on every statement in this part and there are some areas in teaching-learning activities where teachers rarely did the teaching learning activities.

Table 1. Teaching-learning activities used in the classroom

\begin{tabular}{|c|c|c|c|c|}
\hline Statements & $\mathrm{N}$ & Mean & SD & $\begin{array}{l}\text { Cumulative } \\
\text { Mean (SD) }\end{array}$ \\
\hline 1. Teacher explained learning objectives to the students. & 30 & 2.67 & 0.802 & \multirow{8}{*}{$\begin{array}{l}2.18 \\
(0.844)\end{array}$} \\
\hline 2. Teacher discussed the topic according to the learning objectives. & 30 & 3.13 & 0.571 & \\
\hline 3. Teacher explored prior knowledge of students. & 30 & 2.13 & 1.042 & \\
\hline 4. Teacher connected students' prior knowledge with new knowledge. & 30 & 1.90 & 0.995 & \\
\hline 5. Teacher explored students' misconception / alternate conceptions of students. & 30 & 1.43 & 0.774 & \\
\hline 6. Teacher used multiple teaching methods in teaching learning activities. & 30 & 2.47 & 0.860 & \\
\hline 7. Teacher provided opportunity to share students' idea about science topics. & 30 & 2.37 & 0.850 & \\
\hline 8. Teacher used teaching aids in the class. & 30 & 1.40 & 0.855 & \\
\hline
\end{tabular}

Note. $\mathrm{N}=$ Sample size, $\mathrm{SD}=$ Standard deviation.

It is important to discuss the learning objectives before or during the class. Teachers discussed the learning objectives sometimes $(\mathrm{M}=2.67$; $\mathrm{SD}=0.802)$ but there is every possibility to improve it. Moreover, not all the teacher discussed learning objectives in the class and there is a variation among the teachers in respect. Most of the teachers discussed their topics according to learning objectives $(\mathrm{M}=3.13 ; \mathrm{SD}=0.571)$ but it can be improved.

Teachers were irregular in exploring students' prior knowledge $(\mathrm{M}=2.13 ; \mathrm{SD}=1.042)$ and most of the teacher explored students' prior knowledge through questioning in the classroom. Usually they had done it before starting new lesson. Techniques of asking questions for exploring prior knowledge of the students vary from teacher to teacher. Some teachers assessed prior knowledge with the example or knowledge of real life experience. Some teachers did it with the example which was available and/or directly related to textbooks topics. Teachers rarely connected students' prior knowledge with new knowledge $(\mathrm{M}=1.90 ; \mathrm{SD}=0.995)$ and/or explored students' misconceptions ( $\mathrm{M}=1.43 ; \mathrm{SD}=0.774)$ about science.

Teachers sometimes used multiple teaching methods $(\mathrm{M}=2.47 ; \mathrm{SD}=0.860)$ but most of the teachers used only lecture method in their teaching learning activities. Even teachers didn't used alternative way of teaching (discussion, role play, demonstration etc.) if any students fail to understand any topic. Teachers didn't provide well opportunity to share students' idea $(\mathrm{M}=2.37 ; \mathrm{SD}=0.850)$ and most of the teachers didn't encouraged students to talk and share ideas about science in the classroom. Usually, teachers did not permit students to talk or share ideas about any topic discussing in classroom. It was also found that teachers became irritated and rebuked students for trying to talk with his/her classmates. Teachers hardly use teaching aids in the class $(\mathrm{M}=1.40 ; \mathrm{SD}=0.855)$. Actually, most of the teachers didn't use any teaching aids in the class.

During pre and post observation interview, most of the teachers explained that their purpose of teaching learning activity was to provide knowledge about the science topic and help students to learn it. But one teacher who coded as $T_{13}$ explained that her intention was to make students attentive in the class by creating enjoyable classroom environment even if they don't understand the science topic. All the teachers strongly agreed that using teaching aids in science classes is very necessary and they should use teaching aids. Only six teachers told that they use teaching aids sometimes but others told that they rarely use teaching aids.

\subsection{Classroom Assessment Practices}

Assessment is not a separate rather than an integrated task in the classroom. Teachers mainly assess students throughout the class from the beginning till the end of the class. The cumulative mean of classroom assessment practice is 2.27 and SD 0.757 . This mean indicates that teachers did not done well in practicing classroom assessment activity and improvement is required. 
Table 2. Classroom assessment practices

\begin{tabular}{llll}
\hline Statements & N & Mean & $\begin{array}{c}\text { SD } \\
\text { Cumulative Mean } \\
\text { (SD) }\end{array}$ \\
\hline 1. Teacher encouraged students to ask questions. & 30 & 2.20 & 0.805 \\
2. Teacher asked open questions to the students. & 30 & 2.23 & 1.135 \\
3. Teacher asked closed questions to the students. & 30 & 3.13 & 0.681 \\
4. Teacher gave equal opportunities to all students to answer the questions & 30 & 2.83 & 0.699 \\
5. Teacher provided students sufficient time to answer questions. & 30 & 2.87 & 0.776 \\
6. Teacher used self-assessment technique to assess students. & 30 & 1 & 0 \\
7. Teacher used peer assessment technique to assess students. & 30 & 1.60 & 1.003 \\
8. Teacher assessed students through problem solving/investigation work. & 30 & 1.40 & 0.770 \\
9. Teacher kept active all the students in assessment & 30 & 2.77 & 1.073 \\
10. Teacher assessed students orally. & 30 & 3.73 & 0.450 \\
11. Teacher assessed students written (class work). & 30 & 1.35 & 0.850 \\
12. Teacher assessed students' knowledge through individual work. & 30 & 2.97 & 0.490 \\
13. Teacher assessed students' knowledge through group work. & 30 & 1.67 & 1.155 \\
14. Teacher assessed students' lower order learning (Knowledge, understanding, application). & 30 & 2.83 & 0.699 \\
15. Teacher assessed students' higher order learning (Evaluation, analysis, synthesis). & 30 & 1.47 & 0.776 \\
\hline
\end{tabular}

Note. $\mathrm{N}=$ Sample size, $\mathrm{SD}=$ Standard deviation.

Questioning parts were almost dominated by the teachers. It is noticeable that teachers usually asked the questions to the students and the students played the role of answering the questions. Teachers hardly encouraged students to ask questions in the class $(\mathrm{M}=2.20 ; \mathrm{SD}=0.805)$. Most of the teachers didn't give any chance to the students for raising their questions but when teacher gave chance to the students, they did not ask any questions to the teachers. Teachers didn't ask open questions to the students $(\mathrm{M}=2.23 ; \mathrm{SD}=1.135)$. Only a few open questions were asked to the students in few classes during the teaching learning activity. Although teachers were good in asking closed questions $(\mathrm{M}=3.13 ; \mathrm{SD}=0.681)$, improvement is possible. Teachers sometimes gave equal opportunities to all students to answer the questions $(\mathrm{M}=2.83 ; \mathrm{SD}=0.699)$ but most of the time teachers asked questions in the classroom pointing to a particular student. Generally teachers asked questions to the high scorers in the exam or some selected students. They hardly threw questions to the whole class. Most of the teachers didn't provided students sufficient time to answer questions $(\mathrm{M}=2.87 ; \mathrm{SD}=0.776)$. After asking the question the teachers' waited about 5-10 seconds to reply, whenever someone failed teacher switched to another student.

Teacher didn't used self-assessment technique to assess students $(M=1 ; S D=0)$. Teachers also didn't use peer assessment $(\mathrm{M}=1.60 ; \mathrm{SD}=1.003)$ and/or problem solving/investigation work $(\mathrm{M}=1.40 ; \mathrm{SD}=0.770)$ to assess students. During interview they mentioned that these types of assessment are not so effective for students. Sometimes, teachers kept students active in assessment $(\mathrm{M}=2.77$; $\mathrm{SD}=1.073)$ but improvement is required. Actually, except replying the asked questions, students did not take any part in any assessment related activities as well as teaching learning process in the classroom. Most of the teachers told that they couldn't able to use different techniques of assessment or assess all students of the class due to large class size.

Teachers did well in assessing students orally $(\mathrm{M}=3.73 ; \mathrm{SD}=0.45)$ but all the teachers used the most common technique i.e., oral questioning for assessing students learning in the classroom. Teachers didn't assessed students' class work to assess their learning $(\mathrm{M}=1.35$; $\mathrm{SD}=0.850)$. Teachers did assessed students' knowledge through individual work $(\mathrm{M}=2.97 ; \mathrm{SD}=0.490)$ but teachers rarely assessed students through group work $(\mathrm{M}=1.67$; $\mathrm{SD}=1.155$ ). During pre and post observation interview, almost all the teachers plan their assessment through oral question answer method. Some teachers explained they would assess students through class work. But no teacher acknowledged about using self-assessment or peer assessment techniques.

Teachers did moderately well in assessing students' lower order learning $(\mathrm{M}=2.83 ; \mathrm{SD}=0.699)$ but teachers were not assessing higher order learning of students $(\mathrm{M}=1.46$; $\mathrm{SD}=0.776)$. In the classroom teachers asked almost all the questions from text books. Most of the questions were simply knowledge based especially objective questions. Very few teachers asked question which demanded higher order learning. Teachers told that they don't have enough facilities like laboratory, multimedia class room to assess students higher order learning. Besides, assessing students higher order learning within these short period of class time (35-40 minutes) is nearly impossible. 


\subsection{Classroom Feedback}

Generally, teachers provide feedback to the students on the basis of the classroom assessment results or different tasks assigned by the teachers. Feedback is mainly two types- descriptive and evaluative. In this study teachers were mainly focused on evaluative feedback. The cumulative mean of feedback is just 2.06 and standard deviation is 0.692 . It indicates that teachers did very inappropriate in this part.

Table 3. Feedback provided by the teachers during classroom assessment

\begin{tabular}{|c|c|c|c|c|}
\hline Statements & $\mathrm{N}$ & Mean & SD & $\begin{array}{l}\text { Cumulative } \\
\text { Mean (SD) }\end{array}$ \\
\hline 1. Teacher provided correct answer instead provoking/punishing students in their failure. & 30 & 3.07 & 0.521 & \\
\hline 2. Teacher provided oral descriptive feedback. & 30 & 1.27 & 0.691 & \\
\hline 3. Teacher provided oral positive evaluative feedback. & 30 & 3.07 & 0.785 & \\
\hline 4. Teacher provided oral negative evaluative feedback. & 30 & 1.40 & 0.932 & \\
\hline 5. Teacher provided written descriptive feedback. & 30 & 1 & 0 & 2.06 \\
\hline 6. Teacher provided written evaluative feedback. & 30 & 1.20 & 0.610 & $(0.692)$ \\
\hline 7. Teacher provided feedback during teaching learning activity. & 30 & 2.30 & 1.022 & \\
\hline 8. Teacher provided feedback after teaching learning activity. & 30 & 2.67 & 0.758 & \\
\hline 9. Teacher provided feedback individually. & 30 & 2.73 & 0.583 & \\
\hline 10. Teacher provided feedback to whole group. & 30 & 1.93 & 1.015 & \\
\hline
\end{tabular}

Note. $\mathrm{N}=$ Sample size, $\mathrm{SD}=$ Standard deviation.

Most of the teachers provided correct answers when students failed $(\mathrm{M}=3.07 ; \mathrm{SD}=0.521)$ or gave wrong answer but sometimes, in some classroom activities teacher punished students in different ways for different causes. Most of the cases teachers did it when students failed to answer and/or made noise or disturbance in the classroom. Sometimes teachers had been using it as a technique to punish the students who made chaotic and interruption in the classroom and also to warn other students so that they did not do it again. Teachers didn't provide oral $(\mathrm{M}=1.27 ; \mathrm{SD}=0.691)$ or written $(\mathrm{M}=1 ; \mathrm{SD}=0)$ descriptive feedback to the students. Usually feedback in the classroom was taken place in the form of oral evaluative feedback. This type of feedback let students know whether their answer/responses were 'correct' or 'incorrect'. Most of the teachers provided oral positive evaluative feedback $(\mathrm{M}=3.07, \mathrm{SD}=786)$. Teachers were found to be praising students for their correct answers or any good works. "Good", "Very good" etc. were the most commonly uttered word for praising students by the teachers. Very few cases teachers used negative comments as a feedback $(M=1.40 ; S D=0.932)$ when students failed to give right answers of the questions. Teachers also didn't provide written evaluative feedback. Most of the teachers provided feedback to the students after teaching learning activities $(M=2.67$; $\mathrm{SD}=0.758)$. Sometimes teachers provided feedback to all students together as a group $(\mathrm{M}=1.93 ; \mathrm{SD}=1.015)$ but mostly teachers provided individual feedback $(\mathrm{M}=2.73 ; \mathrm{SD}=0.583)$.

\section{Discussion}

Classroom assessment is an essential component in effective teaching learning but in this study classroom assessment as a tool for learning was limited. The study revealed that teachers used oral questioning to assess students in science classroom. Similarly, researchers found that teachers mainly used oral question answer to assess their students in classroom (Ahsan, 2009; Rahman \& Ahmed, 2010). Teachers mostly used oral questioning followed by written tasks, individual works and conversations (Ahmed, Islam, \& Salahuddin, 2015). But Frey and Schmitt (2010) found in a study that paper-pencil test remained the commonly used assessment formats that the teachers used in the classrooms. Similarly, Zhang and Burry-stock (2003) showed that teachers who taught language, arts, science and social science used written test more often than the teachers who taught mathematics.

It is also revealed that teachers didn't use different techniques such as group work, written tasks, practical work or investigation work to assess students. Teachers had very limited ways and methods of assessing their students (Rahman \& Ahmed, 2010). Teachers need to use different strategies to monitor students learning. Ahmed (2011) found that the teachers were not concerned about using different strategies for assessment in the classroom and they did not try to link students' knowledge with their classroom instructions. Ramoroka (2007) argued that teachers should be employed a variety of assessment strategies to capture varied learning of students. No single strategies can be useful to all the students at the same time for the same purpose. Some strategies like written tasks, home works, quizzes, group works, peer works, assignments, probing questions, observation, clinical 
interview and thinking aloud may help teachers to understand the learning processes of students (Rahman \& Ahmed, 2010; Ahmed et al., 2015). When teacher place meaningful assessment at the center of classroom teaching learning, they give insights into their own thinking and growth, and students gain new perspectives on their potential to learn (Susuwele-Banda, 2005).

The present study observed that no teacher practiced self-assessment and very few teachers among the observed classes practiced peer assessment in classroom. Similarly, other researcher found that self and peer assessment practice was absent (Rahman \& Ahmed, 2010). But self-assessment as well as peer assessment is essential to learning (Black \& Wiliam, 1998; Black, Harrison, Lee, Marshall, \& Wiliam, 2004). An approach to self-assessment used by teachers of younger children is to ask learners at the end of a piece or unit of work to look at what they done and try to answer three questions (Black \& Wiliam, 2009): 'What have I done well?', 'What could I have done better?', and 'What do I need to do to improve?'

It is very important for both teachers and students to assess the students before introducing a new science topic in the class. It helps teacher to shape their teaching learning activity and students can prepare them for the upcoming science topic. In this study, teachers were irregular in exploring students' prior knowledge and they hardly connect them with new knowledge. Teachers explored students' prior knowledge through oral question and answer. Similarly, researchers found that teachers mostly used oral questioning to assess students prior knowledge (Ahsan, 2009; Ahmed, 2011). But Ahmed et al. (2015) found that teachers tried to make a connection between students' prior knowledge and new knowledge.

One of the most important tasks of a science teacher is to know the alternative conceptions of students regarding the subject matter (Hackling, 2004). The findings of this research also suggested teachers didn't explore students' misconception about science. Similarly, Ahmed (2011) found that teachers don't emphasize on exploring students misconception and challenge them. Teachers do not use diagnostic assessment to explore students' misconception or alternate conceptions (Ahmed et al., 2015). Diagnostic assessment identify students misconceptions/alternative framework about science topics. Therefore, diagnostic assessments are strong assessment tools that help teachers to plan their teaching learning which meets students' needs.

Classroom questioning was almost dominated by the teachers. It was also found from the existing study that teacher dominates the classroom questioning fully (Ahmed et al., 2015). Most of the time teachers asked closed questions in the classrooms. Open questions were limited in the classroom. It was also found from the existing study that teacher assessed their students by mostly closed questions in the classroom (Ahsan, 2009; Rahman \& Ahmed, 2010; Rahman, Babu, \& Ashrafuzzaman, 2011). But Ahmed et al. (2015) found that teachers were more focused to use open questions to evaluate students learning whereas closed questions were hardly thrown in the class. Effective questioning is an important aspect to engage students in learning activity (Black et al., 2004). Black and Wiliam (1998) states that good questions are hard to generate so teachers should collaborate and draw-critically on outside sources to collect such questions. But this is totally absent in the practices of teachers' classroom assessment. It is found in a study that a balance and strategic use of classroom questioning prompts students to consider their response more thoughtfully listen to and evaluate the responses of others and evaluate their own understanding (Torrance, 2007).

This study explored that teachers mainly assessed students' lower order learning through oral questioning. Very few teachers asked questions which demanded higher order learning. Similarly, other researchers examined that students' higher order learning was almost ignored or rarely focused by the teachers through classroom questioning (Ahsan, 2009; Rahman \& Ahmed, 2010). This study shows that questions posed by teachers in classroom assessment directly and/or indirectly encourages students in rote learning or memorization because teachers asked all questions from textbooks or simply knowledge based especially objective questions. Here, there is a great chance for students to reply any questions through memorization (Ahmed, 2002) as well as students do not have opportunity to be engaged in self-thinking or applying their learned knowledge in a concrete and new situation, nor do they have opportunities to develop higher order learning skill (Crooks, 1988; Ahmed, 2002). All assessment devices were knowledge-based questions, with other cognitive sub-domains left unexplored by the teachers (Babu, 2016). Ahmed (2002) argued that students study science but they do not develop investigation or experimenting ability. There is a need to formulate deep learning through the classroom assessment of students. The questions or tasks should have been designed in such a way so that students can use prior and factual knowledge in solving a problem or carrying out a process, but cannot apply directly on their ability to recall the information (Crooks, 1988).

This study revealed that teachers didn't encouraged students to ask questions in the class. Sometimes, teachers gave equal opportunities to all students to answer the questions but most of the time teachers asked questions in 
classroom pointing to a particular student. Similarly, existing study found that students rarely received any chance for raising the questions to the teachers in the classroom (Ahsan, 2009) and even students didn't ask any questions if they failed to understand lesson or teachers' instructions (Rahman \& Ahmed, 2010). Babu (2016) also found that teachers did not create scope for students to ask questions, and students asked minimum amount of questions in science classes. Every student should have the equal opportunity to reply the asked questions in classroom assessment. Rahman and Ahmed (2010) discovered that teachers favorite learners, high achievers and students sitting in front benches were typically asked questions by teachers and the number of these students was very poor. Most students were deprived from the benefits of classroom assessment.

Findings from this research pointed out that most of the teachers didn't encouraged students to talk and share ideas about science in the classroom. Similarly, researchers found that no teacher encouraged students to talk and share ideas in classroom (Rahman \& Ahmed, 2010). This study found that students only replied the asked questions to them. They didn't take part in any other assessment as well as teaching learning activities of the class. Only a few students were curious to reply teachers' direct questions in the classroom. Rahman and Ahmed (2010) found that it's a common classroom picture that teachers ask questions and students replied. The particular features of the talk between teacher and students are the asking of questions by the teacher; this natural and direct way of checking on learning is often un-productive (Black \& Wiliam, 1998).

Sufficient time allocation for answering is important for students to prepare the anticipated answers. However, teachers do not allow enough time so that students could think out and offered an answer (Black \& Wiliam, 1998). The study revealed that although teachers perceive to provide students sufficient time to answer, in practice most of the teachers did not give sufficient time to think the answers to the students. Very few teachers gave sufficient time (more than 10 seconds) to think the answers to the students. It was also found from the existing study that teachers did not allow enough time for replying every question (Rahman \& Ahmed, 2010). Therefore, students do not try to think for responding the asked questions, even if someone knows the answer, they know that another question will come after a few seconds, so the students do not try to respond (Black \& Wiliam, 1998). This study also revealed that only a few students in a class answered teachers' questions. Most of the students kept them silent to avoid answering because they felt they would not able to provide answers as quickly as selected students could and also as the teachers were expecting from them.

Feedback is one of the most important factors for the students understanding of any subject matter and sustainable learning (Crooks, 1988). Classroom feedback can be provided in many forms. According to Stiggins (1991) teachers mostly use some forms of feedback, such as, verbal communication, nonverbal communication, written comments, performance ratings and test score. The study found that teachers mainly provide oral feedback. Teachers ignored written form of feedback for science classes. In maximum classes teachers didn't provide any feedback. Similarly, several studies found that teachers provide feedback through mainly oral form (Rahman et al., 2011; Ahmed et al., 2015).

This study explored that teachers mainly provided evaluative feedback to students. Generally, teachers let students know whether their answer was 'right' or 'wrong'. Descriptive feedback was absolutely absent in the science classes. In the existing study it was found that teachers generally practice evaluative feedback in the classroom (Ahsan, 2009; Rahman \& Ahmed, 2010; Ahmed, 2011; Ahmed et al., 2015) and descriptive feedback was absent or rarely practiced in classrooms of Bangladesh (Ahsan, 2009). Right-wrong answer feedback focuses on product of students learning rather than learning process. Like grades and marks, right-wrong answer feedback switches students' concentration 'how good I am' (Sadler, 2013). Maclellan (2001) showed in his study that feedback should be in details. Feedback is most effective when it points out strengths in the work as well as areas need to improve (Stiggins, Arter, Chappuis \& Chappuis, 2004). Chappuis and Stiggins (2002) also reported that teacher comment that focus on students work could increase students' motivation and desire to learn. In this study teachers provided feedback after assessing their students. Similarly, previous studies found that the teachers gave feedback to the students after their assessment in the classroom (Ahmed, 2011; Rahman et al. 2011). Feedback should be timely, goal oriented, task oriented and precise. It explores the existing learning in details as well as informs students the ways to achieve goals by fostering learning stage (Rahman \& Ahmed, 2010; Ahmed et. al, 2015). Feedback should be about the particular qualities of students work, with advice what they can do to improve, and should avoid comparisons with others (Black \& Wiliam, 1998).

Findings from this research pointed out that most of the teachers provided correct answers when students failed to answer correctly. Very few teachers punished students or criticize them for not able to provide correct answer rather than giving feedback to them. Ahsan (2009) and Rahman \& Ahmed (2010) also found that sometimes teachers punished students physically instead of providing feedback against failing to respond the questions in the classroom. Negative reinforcement influences on students learning adversely while positive reinforcement 
motivates students in learning process. So, teachers should provide feedback to students as positive reinforcement.

In classroom most of the teachers mainly use lecture method to present their lesson and oral assessment to measure students learning. Students are passive in assessment and their only job is to follow teachers lecture. Students are inattentive in both teaching learning activity and classroom assessment as students are not interested in teachers teaching learning and/or classroom assessments strategies. Finally, it can be concluded that secondary school science teachers' classroom assessment is very inappropriate in Bangladesh. Teachers need to give more effort in using different techniques of classroom assessment to assess students higher order learning. Teachers need to have clear conception about classroom assessment and implement those in their practice as it is their primary duty to bring desired change in the existing classroom assessment system of Bangladesh.

\section{Conclusion}

The classroom assessment practice revealed in this study is very inappropriate and strongly focused to traditional methods of assessing students learning; mainly oral questioning. This information can help educational assessment community to reconsider its training module to focus on teachers particular needs. At present the government is strongly emphasizing the teachers for shifting the focus of classroom assessment to be formative but they are still using it to fulfill the summative purpose of assessment. Teachers mainly aimed to assess students' knowledge or memorization power in the classroom. Teachers may apply different assessment techniques like self-assessment, peer assessment in the classroom according to the needs of students learning. They must be facilitative to the students learning progress rather than students result. The findings of this study shed light on the teachers' different needs of classroom assessment and through professional development necessary changes can be brought. Moreover, to bring a change in science curriculum and policy making, this study can be a point of reference.

\section{Acknowledgement}

All praise to Allah, the Most Beneficent and the Most Merciful. First of all, I state my deep sense of gratefulness to my honorable supervisor Professor Hosne Ara Begum, Dept. of Educational Evaluation and Research, under whose sincere guidance, supervision and support I have been able to complete this study. I am grateful to Associate Professor Mr. Shah Shamim Ahmed, Chairperson, Dept. of Educational Evaluation and Research, who not only provided numerous opportunities for growth, unwavering support and critical feedback in my work but facilitated and prepared me for variety of life changes and challenges. This study would not have been possible without the significant contributions of my wife Monira Akter Mowsumi. I wish to express my appreciation for the help in data collection, raw data analysis, motivation and support provided by her.

\section{References}

Ahmed, M. I. (2011). Assessment (Diagnostic and Formative) Strategies used in the Secondary Science Classroom in Dhaka City (Unpublished masters' thesis). Institute of Education and Research, University of Dhaka, Bangladesh.

Ahmed, S. S. (2002). The Effects of Public Examination on the Process of Students' Learning (Unpublished masters' thesis). Institute of Education and Research, University of Dhaka, Bangladesh.

Ahmed, S. S., Islam, M. S., \& Salahuddin, M. (2015). Classroom Assessment Practices in Urban Secondary Science Classes in Bangladesh. NAEM Journal, 10(19), 32-42.

Ahsan, S. (2009). Classroom Assessment Culture in Secondary Schools of Dhaka City. Teacher's World, 33-34, 231-244.

Ainscow, M. (1988). Beyond the eyes of the monster: Analysis of recent trends in assessment and recording. Support for Learning, 3(3). https://doi.org/10.1111/j.1467-9604.1988.tb00088

Babu, R. (2016). Teaching Science in Bangladesh: Expectation versus Reality. Journal of Education and Learning, 10(3), 244-254.

Bell, B. (2002). The Characteristics of Formative Assessment in Science Education. Hamilton, New Zealand: University of Waikato. https://doi.org/10.1002/sce.1022

Black, P., \& Wiliam, D. (1998). Inside the black box: Raising standards through classroom assessment. Phi Delta Kappan, 80(2), 139-149. https://doi.org/10.1177/003172171009200119

Black, P., \& Wiliam, D. (2009). Developing the theory of formative assessment. Educational Assessment, Evaluation and Accountability, 21(1), 1-40. https://doi.org/10.1007/s11092-008-9068-5 
Black, P., Harrison, C., Lee, C., Marshall, B., \& Wiliam, D. (2004). Working inside the black box: assessment for learning in the classroom. Phi Delta Kappan. 86(1), 9-21. https://doi.org/10.1177/003172170408600105

Brown, S. (2004). Assessment for Learning. Learning and Teaching in Higher Education, 1, 81-89.

Chappuis, S., \& Stiggins, R. J. (2002). Classroom Assessment for Learning. Educational Leadership, 60(1), 40-43.

Crooks, T. J. (1988). The Impact of Classroom Evaluation Practices on Students. Review of Educational Research, 58(4), 438-481. https://doi.org/10.3102/00346543058004438

Earl, L., \& Katz, S. (2006). Rethinking Classroom Assessment with Purpose in Mind: Assessment for learning, assessment as learning, assessment of learning. Western and Northern Canadian Protocol for Collaboration in Education: Governments of Alberta, British Columbia, Manitoba, Northwest Territories, Nunavut, Saskatchewan, and Yukon Territory. Retrieved July 3, 2017, from https://www.wncp.ca/media/40539/rethink.pdf

Frey, B. B., \& Schmitt, V. L. (2010). Teachers' classroom assessment practices. Middle Grades Research Journal, 5(3), 107-117.

Grela, G. (2013). Does weighted average really work? SERVQUAL: review, critique, research agenda. European Journal of Marketing, 30(1), 8-32.

Hackling, M. W. (2004). Assessment in Science. In G. Venville \& V. Dawson (Eds.), The Art of Teaching Science (1st ed., pp. 126-144). National Library of Australia.

Maclellan, E. (2001). Assessment for learning: the differing perceptions of tutors and students. Assessment and Evaluation in Higher Education, 26(4), 307-318. http://dx.doi.org/10.1080/02602930120063466

Rahman, M. F., Babu, R., \& Ashrafuzzaman, M. (2011). Assessment and Feedback Practices in English Language Classroom. Journal of NELTA, 16(1-2), 97-108.

Rahman, M. M., \& Ahmed, S. S. (2010). Classroom Assessment and Student Learning: An Exploration of Secondary School Teacher Practices. NAEM Journal, 5(10), 32-44.

Ramaroka, N. J. (2007). Educators' Understanding of the Premises Underpinning Outcomes-Based Education and its Impact on their Classroom Assessment Practices (Unpublished masters' thesis). University of Pretoria, South Africa. Retrieved July 26, 2017, from http://repository.up.ac.za/bitstream/handle/2263/23799/dissertation.pdf?sequence=1\&isAllowed=y

Sadler, D. R. (2013). Opening up feedback: Teaching learners to see. In S. Merry, M. Price, D. Carless, \& M. Taras (Eds.), Re-conceptualizing Feedback in Higher Education: developing dialogue with students, (Ch. 5, 54-63). London: Routledge.

Stiggins, R. J. (1991). Relevant Classroom Assessment Training for Teachers. Educational Measurement: Issues and Practice, 10(1), 7-12. https://doi.org/10.1111/j.1745-3992.1991.tb00171

Stiggins, R., Arter, J., Chappuis, J., \& Chappuis, S. (2004). Classroom assessment for student learning: Doing it right-using it well. Portland, OR: Assessment Training Institute.

Susuwele-Banda, W. J. (2005). Classroom Assessment in Malawi: Teachers' Perceptions and Practices in Mathematics (Unpublished doctoral dissertation). Virginia Polytechnic Institute, State University, Virginia. Retrieved November 22, 2016, from https://theses.lib.vt.edu/theses/available/etd-02212005-131851/unrestricted/wjsb_dissertation_JAN2005.pdf

Torrance, H. (2007). Assessment as learning? How the use of explicit learning objectives, assessment criteria and feedback in post secondary education and training can come to dominate learning. Assessment in Education, 14(3), 281-294. https://doi.org/10.1080/09695940701591867

Wiliam, D. (2010). An integrative summary of the research literature and implications for a new theory of formative assessment. Handbook of Formative Assessment, 18-40. New York: Routledge.

Zhang, Z., \& Burry-Stock, J. A. (2003). Classroom Assessment Practices and Teachers' Self-Perceived Assessment Skills. Applied Measurement in Education, 16(4), 323-342. https://doi.org/10.1207/S15324818AME1604_4 


\section{Copyrights}

Copyright for this article is retained by the author, with first publication rights granted to the journal.

This is an open-access article distributed under the terms and conditions of the Creative Commons Attribution license (http://creativecommons.org/licenses/by/4.0/). 